Research Article

\title{
Enterprise Production and Emission Reduction Strategy under Carbon Emission Constraint
}

\author{
Simin Zhang $\mathbb{D}^{1,2}$ and Qi Li $\mathbb{i D}^{3,4}$ \\ ${ }^{1}$ Zhuhai City Polytechnic, Zhuhai 519090, China \\ ${ }^{2}$ Lingnan (University) College, Sun Yat-Sen University, Guangzhou 510275, China \\ ${ }^{3}$ Business School, Sun Yat-Sen University, Guangzhou 510275, China \\ ${ }^{4}$ Zhuhai Huafa Investment Holdings Group Co., Ltd., Zhuhai 519000, China \\ Correspondence should be addressed to Qi Li; liqimails@qq.com
}

Received 22 June 2021; Accepted 10 August 2021; Published 25 August 2021

Academic Editor: Marcelo A. Savi

Copyright (C) 2021 Simin Zhang and Qi Li. This is an open access article distributed under the Creative Commons Attribution License, which permits unrestricted use, distribution, and reproduction in any medium, provided the original work is properly cited.

\begin{abstract}
According to China's 14th Five-Year Development Plan, China aims to peak its carbon emissions by 2030 and achieve carbon neutral by 2060, which will be a major strategy for China to implement in the coming period of time. All kinds of industries need to take the industry characteristics into account and gradually form relative carbon reduction targets according to the National Carbon Summit Action Program. Under the constraints of carbon emission reduction, enterprises face trade-off when making emission reduction decisions. How to systematically optimize the profitable and environmentally friendly decisions, under the consideration of carbon emission production, is gradually becoming a main concern of regulated enterprises. In this paper, a Cournot game model is constructed to explore optimal production carbon abatement decisions for two oligopolistic firms, under the governance of a cap-and-trade mechanism. Real case data collected from China's airlines is an example to test the validity of our model. The qualitative analysis shows that, through a reasonable output and emission reduction investment, companies are capable of efficiently minimizing the negative impact brought about by the carbon trading system. A numerical experiment indicates that the companies on one side can reach a decision equilibrium in some circumstances, but on the other side, there exists a lack of incentive to reduce their emissions. Additional government incentives or increased investment in technological improvements will be needed to encourage companies to further reduce carbon emissions. In this paper, while analyzing the choice of emission reduction strategy for enterprises under the carbon trading system, it also provides effective emission reduction approaches for the government and industry managers, hoping to provide some references for the establishment of emission reduction system and policy formulation.
\end{abstract}

\section{Introduction}

At the end of the 20th century, with the rapid development of industrialization, the greenhouse effect caused by carbon emissions began to attract widespread attention worldwide. In 1997, the United Nations Framework Convention on Climate Change (UNFCCC) signed the first global-wide agreement on climate change, the Kyoto Protocol. In December 2015, 200 party-member countries in Paris reached the "Paris agreement" and developed a "nonretreat" ratchet locking mechanism. In this context, governments have begun pushing related policies and devising trading mechanisms to enhance the regulation intensity, while companies are required to keep constantly reinforcing their low-carbon investments. China will scale up its intended Nationally Determined Contributions by adopting more vigorous policies and measures. $\mathrm{Xi}$ Jinping, General Secretary of China, promised at the 75th UN General Assembly: "China aim to have carbon dioxide emissions peak before 2030, and strive to achieve carbon neutralization by 2060." At the end of 2020, the Central Economic Work Conference made it clear that doing a good job of carbon peak and carbon neutral will be one of the eight key tasks in 2021. Carbon peak and carbon neutral will be a major strategy for China in the coming period of time. 
This paper is motivated to explore the optimal production and emission strategies for the companies in a competitive environment, under the governance of the carbon trading mechanism. In order to simplify the modeling framework, two oligopolistic firms are considered to be in a Cournot gaming model. They are assumed to trade in an EU-ETS-like system. The implementation process of such a system is gradually advancing, which can be divided into three stages: the first stage, defined as "learning-by-doing," addresses no requirement but monitors (measures) the emission quantity during the firm's production process. In the second stage, a cap-and-trade mechanism is launched to regulate the industrial carbon emissions against the quota that was set by the government based on the emission level of the firms in the first stage. If, by the end of the second stage, the actual emissions exceed the quota, the company will be required to purchase its surplus volume from the carbon market. If the emission is below the quota, on the contrary, the company is entitled to sell the emission difference to the carbon market. In the third stage, a new quota will be assigned to the company based on the actual emission from the second stage and so forth. Essentially, the mechanism is designed to impose a gradually enhanced regulation to encourage the firms to reduce their emissions.

Before analyzing the emission reduction strategy, we need to first understand the related trade-offs existing in corporate decisions, including its production output and emission abatement investments: if the company requires too much emission reduction, the corresponding cost will be sharply increased. Then, such cost would be possibly transferred to customers through pricing, unless the products are subsidized by the government. On the contrary, if the total emissions during the monitoring period exceed the quota, extraemission costs will be charged to the company. Therefore, an appropriate plan for controlling the company's emissions during the regulation period is the main concern of this paper. A two-stage Cournot game model will be constructed to qualitatively discuss the optimal emission reduction strategies, with discussion on related managerial insights regarding the oligopolistic market's capand-trade mechanism. A real data sample collected from a Chinese airline company will be used to test the validity of our model. With the result, we expect to provide firms, not necessarily those anchored in the airline industry, with decision-making suggestions for resolving their production plan for a low-carbon regulation environment.

The paper is organized as follows. First, we review the related literature to our topic in Section 2. Then, the problem is modeled in Section 3, with the qualitative analysis addressed in Section 4. The numerical experiment is put in Section 5. Section 6 concludes the paper. The paper finds that, through reasonable output and emission reduction investment, companies are capable of efficiently minimizing the negative impact of the carbon trading system.

\section{Literature Review}

For macrolevel research, $\mathrm{Li}$ and $\mathrm{Li}$ [1] took 30 provinces in China as the research object and constructed a spatial econometric model to investigate the impact of energy investment and economic growth on carbon emission reduction. Ma et al. [2] established the model of the duopoly automobile manufacturers. They considered a single period game to derive the optimal solutions, finding that government intervention policies can maximize the social welfare. Madani and Rasti-Barzoki [3] analyzed the impact of government and the interactive decision-making process between the government and supply chain on a company's green implementations. Similar to our current study, the authors considered competition, while we use a static gaming model that does not involve government decisions.

The above research provides a lot of ideas and results worth learning, including how to interpret policies and treaties and the possible impacts of different policies on countries and enterprises. On the sector level, Feng et al. [4], through a data envelopment analysis, stated that the potential of emission reduction exists in three facets, including structure, technology, and management. Babiker [5] considered an oligopoly model with an increasing margin to describe the interactive decision-making process between energy-intensive companies. Sabzevar et al. [6] studied the relation between corporate profitability and cap-and-trade regulations. They built a game-theoretic Cournot model with two competitive firms producing goods. Different from ours, production volumes for each firm at the equilibrium are determined. Wen et al. [7] have investigated the asymmetric relationship between the carbon emission trading market and stock market in China by using the nonlinear autoregressive distributed lag (NARDL) model. The results show that, on the sector level, carbon emission trading price is significantly related to some energy intense sectors and financial sector stock market.

Compared to the sector-level research, from the operation's perspective, we focus more on management. In the competitive market, price competition is one of the most critical factors for both manufacturers and consumers. Xu et al. [8] studied the pricing and production decisions through a made-to-order supply chain under the cap-andtrade mechanism. Through the evolutionary game model, Tong et al. [9] found that the emission cap, the market price of carbon credits, and consumers' preference for low-carbon products are the key factors affecting the behavior of retailers and manufacturers in the retailer-led supply chain. Cao et al. [10] studied the optimal production and pricing decisions of two firms in a dual-channel supply chain selling both remanufactured and new products under remanufacturing subsidy policy (RSP) and carbon tax policy (CTP), respectively, and examined which policy is better for the society.

Many scholars have cast light on environment-friendly operation. The following research studies are based on the manufacturer's production process with green production or technology. Lee [11] examined the problem of jointly determining optimal order quantity and investment in carbon emissions reduction in the EOQ mode. The investment reduces the carbons emitted per replenishment and per unit produced. Sinaki et al. [12] presented a weighted multiobjective mixed-integer-nonlinear programming model to 
integrate manufacturing scheduling and environmentally sustainable supply chain network (SCN). Their result showed that consumers' low-carbon sensitivity and sales strategy jointly affected a firm's profitability. Chen et al. [13] examined the behavior change in warehouse management decisions under the cap-and-trade emission policy and explored the role of green technology investment in managing the tradeoffs between the economic and environment performances of warehousing operations.

Through literature review, it can be seen that scholars have made certain progress in discussing enterprise operation and management under carbon emission policy, laying a foundation for subsequent research, but there are still some deficiencies. On the one hand, most of the existing literatures include carbon trading and market competition into the model, respectively, and compare and analyze their influence on enterprise decision-making, while ignoring the increasingly important parallel situation in reality. On the other hand, most of the existing studies focus on the discussion of pricing, storage, supply chain, and other decisions of enterprises under the carbon policy, while the research on the production and emission reduction strategies of enterprises in the process of low-carbon transformation is not sufficient. Few scholars have studied how to determine the optimal production strategy and emission reduction strategy in competitive enterprises from the perspective of profit maximization.

Compared with their paper, there are three major differences in our current work. Firstly, we focus on the competitive decisions between the firms already in a market, rather than an enter-response strategy; secondly, we consider a two-stage model whereas the last paper essentially used a single-stage one, although the authors constructed a time-line event for the gaming process; thirdly, the operation of the carbon trading system is specifically considered in our paper; e.g., in charge of quota allocations and the gradual reduction of a free quota.

\section{Model and Analysis}

A two-stage decision-making model is constructed on behalf of the companies. The corresponding timeline is listed in Figure 1 as follows. History $(t=0)$ : the company is required to accept the monitor on its total emissions during this period; stage $1(t=1)$ : the transit/base-line period. In this period, the emission quota is distributed to the regulated companies according to the historical emission quantity from the last period and the corresponding industrial level of the current period; stage $2(t=2)$ : the implementation period. In this period, a free emission quota is distributed according to the industrial level but decreased annually. The two-stage model is based on stage $1(t=1)$ and stage $2(t=2)$.

3.1. Assumptions. Related assumptions behind the current topic are listed as follows:

(1) Assume that there are two oligopolistic firms that sell a homogenous product in a market. It also means that there is no other firm that competes with them in this kind of a product market.

(2) Assume the price is linearly correlated with output and the output is equal to the market demand. Based on assumption (1), this implies that the price is determined by the two competitive firms.

(3) The emission quota is assumed to be distributed to the firms for free, without considering an auction mechanism.

(4) Assume that the low-carbon regulation is mandatory for a firm. That is, if the monitored emission is larger/ less than the quota, the firm is required/entitled to compensate/save the difference from the carbon market.

(5) The two firms are assumed to have different emission efficiencies.

3.2. Notations. The major notations that will be used in this paper are listed in Table 1.

Based on the above notions, the inverse demand function is formulated as $P_{1}=a-\gamma_{1} q_{11}-\gamma_{2} q_{21}$ and $P_{2}=a-$ $\gamma_{1} q_{12}-\gamma_{2} q_{22}$ without loss of generality, where $a$ denotes the total market share for both of the firms.

3.3. Two-Stage Model. Consider that the Carbon Trading Strategy is launched in the historical period when the firm's decision as we express below will affect the quota it will gain in the next stage. The historical output in this period is denoted by $q_{1}^{0}$ and $q_{2}^{0}$ for firm 1 and firm 2, respectively. The output ratio of each firm can be represented as $r_{1}=q_{1}^{0} /\left(q_{1}^{0}+q_{2}^{0}\right)$, with $r_{1} \in(0,1)$, and $r_{2}=q_{2}^{0} /\left(q_{1}^{0}+q_{2}^{0}\right)$, with $r_{2} \in(0,1)$; and, both will be used to determine the quota in stage 1 . In order to distinguish the firms' capacity, let $q_{1}^{0} \in\left[0, q_{1-\text { max }}^{0}\right], q_{2}^{0} \in\left[0, q_{2-\max }^{0}\right]$ and $q_{1-\max }^{0}>q_{2-\max }^{0}$.

In stage 1 , the base quota, say $R$, is delivered to the firms according to their output ratio calculated in the last stage, i.e., the historical stage. Then, the quota freely distributed in practice for each year within the same period is usually $\tau_{1}$, with $\tau_{1} \in(0,1)$, multiplied with the quota in the previous year. Then, the quota in the $i$ th year should be $R_{i}=\tau_{1}^{i-1} R$, in which $i=\{0,1, \ldots, n\} . n$ is the number of years in stage 1 . That is to say, the total quota delivered to firm 1 and 2 in the first stage will be $R_{1}=r_{1} \sum_{1}^{n} \tau_{1}^{i-1} R$ and $R_{2}=r_{2} \sum_{1}^{n} \tau_{1}^{i-1} R$, respectively. For simplicity of our modeling analysis, let $\delta_{1}=$ $\sum_{1}^{n} \tau_{1}^{i-1}$; thus, we have $R_{1}=\delta_{1} r_{1} R$ and $R_{2}=\delta_{1} r_{2} R$, respectively.

For the output in the first stage, the two firms have to decide $q_{11}$ and $q_{21}$ with respect to the corresponding unit emissions of $\alpha_{1}$ and $\alpha_{2}$, respectively. According to our assumptions above, we have $\alpha_{1}<\alpha_{2}$ due to their difference in energy efficiency.

Accordingly, the profit in the first stage can be formulated as 


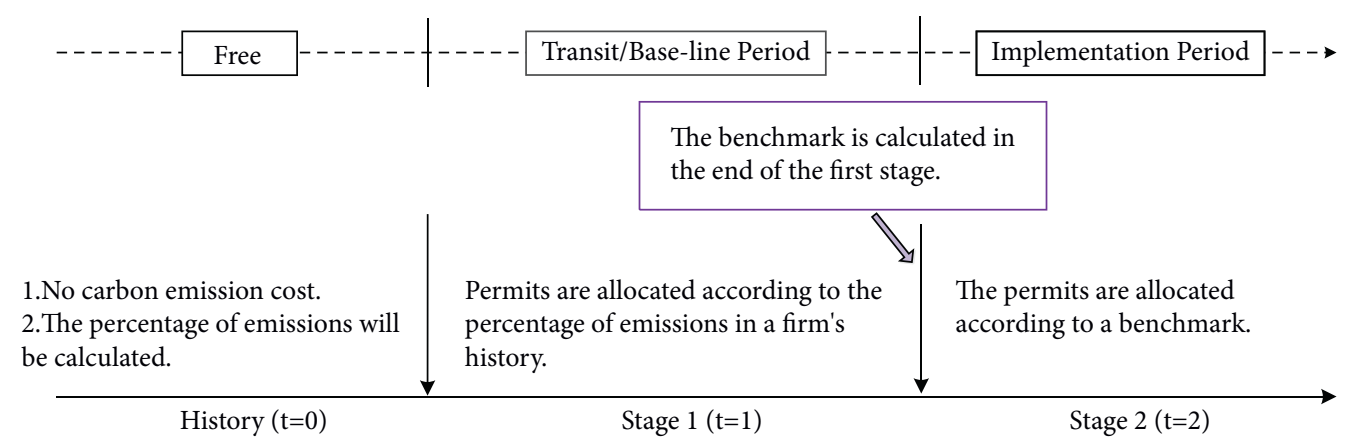

Figure 1: Time-line events.

TABLE 1: Related notations.

\begin{tabular}{lc}
\hline$\gamma_{1}=$ & Historical output ratio of firm 1 \\
$\gamma_{2}=$ & Historical output ratio of firm 2 \\
$P_{1}=$ & Product price in stage 1 that is dependent on the production decision \\
$q_{11}=$ & Output decision of firm 1 in stage 1 \\
$q_{21}=$ & Output decision of firm 2 in stage 1 \\
$P_{2}=$ & Product price in stage 2 that is dependent on the production decision \\
$q_{12}=$ & Output decision of firm 1 in stage 2 \\
$q_{22}=$ & Output decision of firm 2 in stage 2 \\
$Z_{1}=$ & Carbon price in stage 1 that is exogenous determined by the carbon market \\
$Z_{2}=$ & Carbon price in stage 2 that is exogenous determined by the carbon market \\
\hline
\end{tabular}

$$
\begin{aligned}
\pi_{11} & =P_{1} q_{11}-Z_{1}\left(\alpha_{1} q_{11}-\delta_{1} r_{1} R\right), \\
& =\left(a-\gamma_{1} q_{11}-\gamma_{2} q_{21}\right) q_{11}-Z_{1}\left(\alpha_{1} q_{11}-\delta_{1} r_{1} R\right), \\
\pi_{21} & =P_{1} q_{21}-Z_{1}\left(\alpha_{2} q_{21}-\delta_{1} r_{2} R\right), \\
& =\left(a-\gamma_{1} q_{11}-\gamma_{2} q_{21}\right) q_{21}-Z_{1}\left(\alpha_{2} q_{21}-\delta_{1} r_{2} R\right) .
\end{aligned}
$$

For each firm, the first equation denotes the revenue obtained by selling products, while the second equation denotes the emissions generated by production. Given $q_{11}$ and $q_{21}$, the emission benchmark of the industry, $\bar{\alpha}$, can be determined by the weighted sum of each firm's output:

$$
\bar{\alpha}=\frac{\alpha_{1} q_{11}+\alpha_{2} q_{21}}{q_{11}+q_{21}}=\frac{q_{11}}{q_{11}+q_{21}} \alpha_{1}+\frac{q_{21}}{q_{11}+q_{21}} \alpha_{2} .
$$

The delivery of the quota in stage 2 is based on the benchmark proposed above, which, in other words, means that the firm's production decision in the first stage will affect the quota it receives in the second stage. Then, we denote the quota in stage 2 by $\tau_{2}, \tau_{2} \in(0,1)$, and we have the quota for the two firms formulated as $\delta_{2} \bar{\alpha} \cdot q_{12}$ and $\delta_{2} \bar{\alpha} \cdot q_{22}$, respectively, in which $\delta_{2}=\sum_{1}^{\infty} \tau_{2}^{i-1}$. As we assume that both the firms will reduce their emissions in the second stage with technology improvements, we can denote the reduction ratio by $\beta_{1} \in(0,1)$ and $\beta_{2} \in(0,1)$ for them. Set the feasible set of the variables to open, without the loss of generality, by considering that the emissions are always strictly positive no matter how much resource each firm inputs. Consequently, smaller $\beta$ indicates larger efforts on emissions reduction.

Correspondingly, the improvement cost for each two variables is assumed as $\theta_{1}$ and $\theta_{2}$, respectively. Following the previous assumption, we have $\theta_{1}>\theta_{2}$, given the same reduction ratio for the two firms. In describing the reduction costs, a quadratic function of $\beta$ is established following the conventional use of expressing the technology improvement. Parameter $\theta$ is applied to denote improvement efficiency. In summary, the profit function for both firms in the second stage can be formulated as follows:

$$
\begin{aligned}
& \pi_{12}=P_{2} q_{12}-Z_{2}\left(\beta_{1} \alpha_{1} q_{12}-\delta_{2} \bar{\alpha} q_{12}\right)-\frac{1}{2} \theta_{1}\left(1-\beta_{1}\right)^{2}, \\
& \pi_{22}=P_{2} q_{22}-Z_{2}\left(\beta_{2} \alpha_{2} q_{22}-\delta_{2} \bar{\alpha} q_{22}\right)-\frac{1}{2} \theta_{2}\left(1-\beta_{2}\right)^{2} .
\end{aligned}
$$

Note that the firm's decision in the first stage affects the carbon trading outcome in the consequent period, through $\bar{\alpha}$. The second term in the function denotes the trading payoff from the carbon market after the investment of emission abatement.

3.4. Emission Reduction. Based on our assumptions, the decision-making process mainly incorporates the output $q$ and reduction effort $\beta$, namely, each firm can decide how much it wants to produce and to what degree its marginal emissions should be reduced. In the following, we use firm 1 as an example to illustrate our analysis, considering the symmetry of the decision-making process of the two firms.

Proposition 1. When $0<\alpha_{1}<\alpha_{1}^{\prime \prime \prime}=\sqrt{2 B / A}$, where $A=2 Z_{2}^{2}$ and $B=3 \gamma_{1} \theta_{1}$, the firm's optimal solution can be denoted as follows: 


$$
\begin{aligned}
q_{12}^{*} & =\frac{\left(\mathrm{a} \theta_{1} \theta_{2}-2 Z_{2} \alpha_{1} \theta_{1} \theta_{2}+Z_{2} \alpha_{2} \theta_{1} \theta_{2}+Z_{2} \delta_{2} \bar{\alpha} \theta_{1} \theta_{2}\right)\left[3 \gamma_{2} \theta_{1} \theta_{2}-2\left(Z_{2} \alpha_{2}\right)^{2} \theta_{1}\right]-\left(\mathrm{a} \theta_{1} \theta_{2}-2 Z_{2} \alpha_{2} \theta_{1} \theta_{2}+Z_{2} \alpha_{1} \theta_{1} \theta_{2}+Z_{2} \delta_{2} \bar{\alpha} \theta_{1} \theta_{2}\right)\left(Z_{2} \alpha_{2}\right)^{2} \theta_{1}}{\left[3 \gamma_{1} \theta_{1} \theta_{2}-2\left(Z_{2} \alpha_{1}\right)^{2} \theta_{2}\right]\left[3 \gamma_{2} \theta_{1} \theta_{2}-2\left(Z_{2} \alpha_{2}\right)^{2} \theta_{1}\right]-\left(Z_{2} \alpha_{1}\right)^{2}\left(Z_{2} \alpha_{2}\right)^{2} \theta_{1} \theta_{2}}, \\
\beta_{1}^{*} & =\frac{z_{2} \alpha_{1}\left(\mathrm{a}+Z_{2} \beta_{2} \alpha_{2}+Z_{2} \delta_{2} \bar{\alpha}\right)-3 \gamma_{1} \theta_{1}}{2\left(z_{2} \alpha_{1}\right)^{2}-3 \gamma_{1} \theta_{1}},
\end{aligned}
$$

for the second stage.

Considering that the specific form of the optimal output for the first stage $q_{11}{ }^{*}$ is too tedious to record here, we neglect to report it without having any significant impact on our result.

Proof of Proposition 1. Based on the sufficient condition $\left(-z_{2} \alpha_{1}\right)^{2}-\left(-2 r_{1}\right)\left(-\theta_{1}\right) \leq 0$ as we let $\alpha_{1}^{\prime \prime \prime}=\sqrt{2 B / A}, A=2 Z_{2}^{2}$, and $B=3 \gamma_{1} \theta_{1}$, the proof of the existence of the optimal solution is intuitive. In this case, solutions $q_{12}=\left(a-2 Z_{2} \beta_{1} \alpha_{1}+Z_{2} \beta_{2} \alpha_{2}+Z_{2} \delta_{2} \bar{\alpha}\right) / 3 \gamma_{1}, \quad q_{22}=\left(a-2 Z_{2}\right.$ $\left.\beta_{2} \alpha_{2}+Z_{2} \beta_{1} \alpha_{1}+Z_{2} \delta_{2} \bar{\alpha}\right) / 3 \gamma_{2}$, and $\beta_{1}=1-\left(z_{2} \alpha_{1} q_{12} / \theta_{1}\right)$ can be derived by taking the first derivative of formulations (3) and (4) for $q$ and $\beta$. Solving the above group of equations, $q_{12}^{*}$ and $\beta_{1}^{*}$ are obtained. Since the output decision of stage 1 affects the firms' performance in both the first and second stages, the profits from the two stages can be summed as follows:

$$
\begin{aligned}
& L 1=\left(a-\gamma_{1} q_{11}-\gamma_{2} q_{21}\right) q_{11}-Z_{1}\left(\alpha_{1} q_{11}-\delta_{1} r_{1} A\right)+\left(a-\gamma_{1} q_{12}-\gamma_{2} q_{22}\right) q_{12}-Z_{2}\left(\beta_{1} \alpha_{1} q_{12}-\delta_{2} \bar{\alpha} q_{12}\right)-\frac{1}{2} \theta_{1}\left(1-\beta_{1}\right)^{2} \\
& L 2=\left(a-\gamma_{1} q_{11}-\gamma_{2} q_{21}\right) q_{21}-Z_{1}\left(\alpha_{2} q_{21}-\delta_{1} r_{2} A\right)+\left(a-\gamma_{1} q_{12}-\gamma_{2} q_{22}\right) q_{22}-Z_{2}\left(\beta_{2} \alpha_{2} q_{22}-\delta_{2} \bar{\alpha} q_{22}\right)-\frac{1}{2} \theta_{2}\left(1-\beta_{2}\right)^{2} .
\end{aligned}
$$

Simplifying the equations after taking the first-order condition (F.O.C.), we have

$$
\begin{aligned}
& \left(q_{11}+q_{21}\right)^{2}\left(a-2 \gamma_{1} q_{11}-\gamma_{2} q_{21}-Z_{1} \alpha_{1}\right)=Z_{2} \delta_{2} q_{12}\left(\alpha_{2}-\alpha_{1}\right) q_{21}, \\
& \left(q_{11}+q_{21}\right)^{2}\left(a-\gamma_{1} q_{11}-2 \gamma_{2} q_{21}-Z_{1} \alpha_{2}\right)=Z_{2} \delta_{2} q_{22}\left(\alpha_{1}-2\right) q_{11} .
\end{aligned}
$$

Solving the above group of equations, the result $q_{11}^{*}$ is obtained. So far, the proposition is proved.

Remark 1. The optimal solution for the first stage of firm 1 can be qualitatively derived given $q_{12}^{*}, q_{22}^{*}, \beta_{1}^{*}$, and $\beta_{2}^{*}$. Note that $q_{22}^{*}$ and $\beta_{2}^{*}$ can be obtained by following the above proposition. Since the specific form of $q_{11}^{*}$ is too tedious to record, its expression is neglected here but available in supplemental material online at https://user.qzone.qq.com/ 117673553. Corresponding numerical experiment is left for later in this paper.

\section{Sensitivity Analysis}

The impact of different parameters to the result will be described in this section. Setting $C=\left(a+Z_{2} \beta_{2} \alpha_{2}\right)$ $Z_{2}+Z_{2}^{2} \delta_{2}\left(q_{21} /\left(q_{11}+q_{21}\right)\right), \quad D=Z_{2}^{2} \delta_{2}\left(q_{11} /\left(q_{11}+q_{21}\right)\right)$, and $\beta_{1}^{*}=\left(C \alpha_{1}+D \alpha_{1}^{2}-B\right) /\left(A \alpha_{1}^{2}-B\right)$, two properties can be derived in the following.

Property 1. When $(B D-A B)^{2}>A B C^{2}$ and $\mathrm{A}<\mathrm{D}, \beta_{1}$ is the descending function of $\alpha_{1}$ (cf. Figure 2); when $(B D-A B)^{2}>A B C^{2}$ and $\mathrm{A}>\mathrm{D}$, three possible cases need to be considered.
Case 1. $\beta_{1}$ is the descending function of $\alpha_{1}$, when $3 A B$ $C^{2}<2(A B-B D)^{2}-2(A B-B D) \sqrt{(A B-B D)^{2}-A B C^{2}}$

(Figure 3(a));

Case 2. Under the condition $3 A B C^{2}>2(A B-B D)^{2}-$ $2(A B-B D) \sqrt{(A B-B D)^{2}}-A B C^{2}$, there are three branches: $\beta_{1}$ is the descending function of $\alpha_{1}$ while $0<\alpha_{1}<\alpha_{1}^{\prime}, \beta_{1}$ is the increasing function of $\alpha_{1}$ while $\alpha_{1}^{\prime}<\alpha_{1}<\alpha_{1}^{\prime \prime}$, and $\beta_{1}$ is the descending function of $\alpha_{1}$ while $\alpha_{1}^{\prime \prime}<\alpha_{1}<\alpha_{1}^{\prime \prime \prime}$ (Figure 3(b)).

Case 3. Under the condition $2(A B-B D)^{2}-2(A B-B D)$ $\sqrt{(A B-B D)^{2}-A B C^{2}}<3 A B C^{2}<2(A B-B D)^{2}+2(A B-$ $B D) \sqrt{(A B-B D)^{2}-A B C^{2}}$, there are two branches: $\beta_{1}$ is the descending function of $\alpha_{1}$ while $0<\alpha_{1}<\alpha_{1}^{\prime} ; \beta_{1}$ is the increasing function of $\alpha_{1}$ while $\alpha_{1}^{\prime}<\alpha_{1}<\alpha_{1}^{\prime \prime \prime}$ (Figure 3(c)).

Proof of Property 1. Applying the first derivative of $\beta_{1}$ to $\alpha_{1}$, we have $\left(\mathrm{d} \beta_{1} / \mathrm{d} \alpha_{1}\right)=\left(\left(C+2 D \alpha_{1}\right) /\left(A \alpha_{1}^{2}-B\right)\right)-$ $\left(2 A \alpha_{1}\left(C \alpha_{1}+D \alpha_{1}^{2}-B\right) /\left(A \alpha_{1}^{2}-B\right)^{2}\right)$. To ensure its positivity, we should have $(B D-A B)^{2}>A B C^{2}$ and $\alpha_{1}^{\prime}<\alpha_{1}<\alpha_{1}^{\prime \prime}$, where $\alpha_{1}^{\prime}=\left((A B-B D)-\sqrt{(A B-B D)^{2}-A B C^{2}}\right) / A C$ and $\alpha_{1}^{\prime \prime}=\left((A B-B D)+\sqrt{(A B-B D)^{2}-A B C^{2}}\right) / A C$. Similarly, $\left(\mathrm{d} \beta_{1} / \mathrm{d} \alpha_{1}\right)<0$ when $\alpha_{1}<\alpha_{1}^{\prime}$ or $\alpha_{1}>\alpha_{1}^{\prime \prime}$. On the contrary, when $A<D$, we have $(A B-B D)<0$ and $\alpha_{1}^{\prime \prime}<0$. That is, $\alpha_{1}^{\prime}<\alpha_{1}^{\prime \prime}<0<\alpha_{1}^{\prime \prime \prime}$. Then, $\beta_{1}$ falls in the decreasing function region with respect to $\alpha_{1}$. 


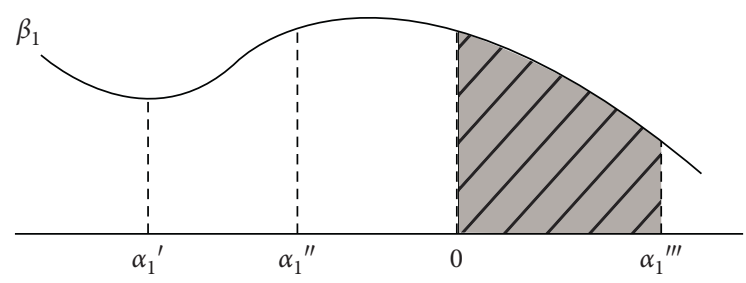

Figure 2: Graphic exhibition for the first part of Property 2. $(B D-A B)^{2}>A B C^{2}$ and $A<D$.

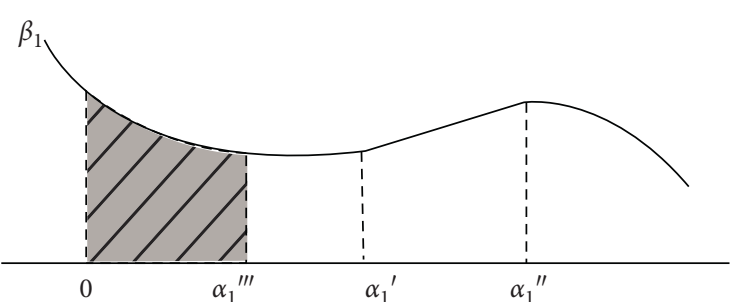

(a)

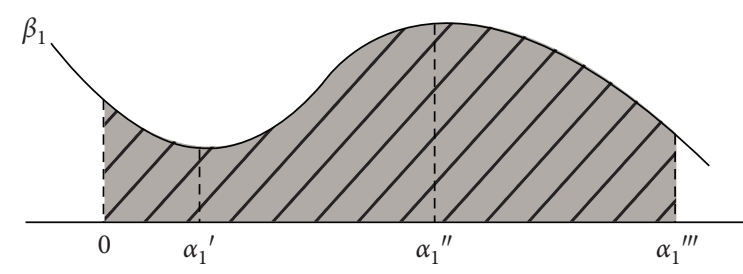

(b)

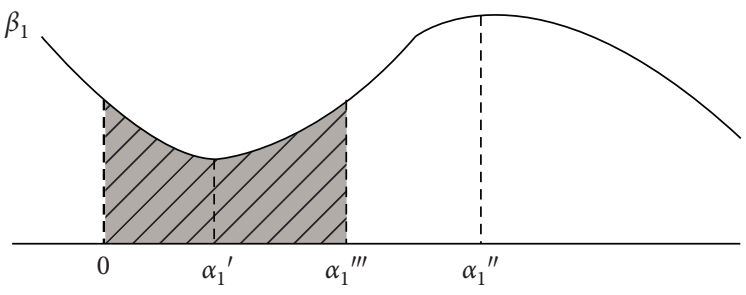

(c)

Figure 3: (a) Case 1: $(B D-A B)^{2}>A B C^{2}, \quad \mathrm{~A}>\mathrm{D}$, and $3 A B C^{2}<2(A B-B D)^{2}-2(A B-B D) \sqrt{(A B-B D)^{2}-A B C^{2}}$. (b) Case 2: $(B D-A B)^{2}>A B C^{2}, \mathrm{~A}>\mathrm{D}$, and $3 A B C^{2}>2(A B-B D)^{2}-2(A B-B D) \sqrt{(A B-B D)^{2}-A B C^{2}}$. (c) Case $3:(B D-A B)^{2}>A B C^{2}, A>D$, and $2(A B-B D)^{2}-2(A B-B D) \sqrt{(A B-B D)^{2}-A B C^{2}}<3 A B C^{2}<2(A B-B D)^{2}+2(A B-B D) \sqrt{(A B-B D)^{2}-A B C^{2}}$.

For the second part, with respect to $(B D-A B)^{2}>A B C^{2}$ and $A>D$, we prove the three cases as follows.

Proof of Case 1. When $A>D$, we have $0<\alpha_{1}^{\prime}<\alpha_{1}^{\prime \prime}$. When $3 A B C^{2}<2(A B-B D)^{2}-2(A B-B D)$ $\sqrt{(A B-B D)^{2}-A B C^{2}}$, we have $\sqrt{2 B / A}$ $<\left((A B-B D)-\sqrt{(A B-B D)^{2}-A B C^{2}}\right) / A C$ and $\alpha_{1}^{\prime \prime \prime}<\alpha_{1}^{\prime}$, namely, $0<\alpha_{1}^{\prime \prime \prime}<\alpha_{1}^{\prime}<\alpha_{1}^{\prime \prime}$. Then, $\beta_{1}$ falls in the decreasing function region.

Proof of Case 2. When $A>D$, we have $0<\alpha_{1}^{\prime}<\alpha_{1}^{\prime \prime \prime}$. At the same time, when $3 A B C^{2}>2(A B-B D)^{2}+2(A B-B D)$ $\sqrt{(A B-B D)^{2}-A B C^{2}}$, we have $\sqrt{2 B / A}>((A B-B D)$ $\left.+\sqrt{(A B-B D)^{2}-A B C^{2}}\right) / A C$; then, $\alpha_{1}^{\prime \prime}<\alpha_{1}^{\prime \prime \prime}$. In conclusion, $0<\alpha_{1}^{\prime}<\alpha_{1}^{\prime \prime}<\alpha_{1}^{\prime \prime \prime}$, and $\beta_{1}$ is the descending function of $\alpha_{1}$ when $0<\alpha_{1}<\alpha_{1}^{\prime} ; \beta_{1}$ is the increasing function of $\alpha_{1}$ when $\alpha_{1}^{\prime}<\alpha_{1}<\alpha_{1}^{\prime \prime}$; and, $\beta_{1}$ is the descending function of $\alpha_{1}$ when $\alpha_{1}^{\prime \prime}<\alpha_{1}<\alpha_{1}^{\prime \prime \prime}$.

Proof of Case 3. When $A>D$, we have $0<\alpha_{1}^{\prime}<\alpha_{1}^{\prime \prime}$; simultaneously, when $2(A B-B D)^{2}-2(A B-B D)$
$\sqrt{(A B-B D)^{2}-A B C^{2}}<3 A B C^{2}<2(A B-B D)^{2}+2(A B-$ $B D) \sqrt{(A B-B D)^{2}-A B C^{2}}$, we have $\alpha_{1}^{\prime}<\alpha_{1}^{\prime \prime \prime}<\alpha_{1}^{\prime \prime}$.

In conclusion, $0<\alpha_{1}^{\prime}<\alpha_{1}^{\prime \prime \prime}<\alpha_{1}^{\prime \prime}$, and $\beta_{1}$ is the descending function of $\alpha_{1}$ when $0<\alpha_{1}<\alpha_{1}^{\prime}$; or, $\beta_{1}$ is the increasing function of $\alpha_{1}$ when $\alpha_{1}^{\prime}<\alpha_{1}<\alpha_{1}^{\prime \prime \prime}$.

So far, Property 1 is proved.

The first part of the above property is graphically shown in Figure 2, while the graphical description on the three cases of the second part of the property are reported in Figures 3(a)-3(c), respectively.

Property 2. When $2\left(Z_{2} \alpha_{1}\right)^{2}-3 \gamma_{1} \theta_{1}>0, \beta_{1}$ is the increasing function of $\beta_{2}$. When $2\left(Z_{2} \alpha_{1}\right)^{2}-3 \gamma_{1} \theta_{1}<0, \beta_{1}$ is the descending function of $\beta_{2}$. When $2\left(Z_{2} \alpha_{1}\right)^{2}-3 \gamma_{1} \theta_{1}>0, \beta_{1}$ is the increasing function of $\alpha_{2}$; and, when $2\left(Z_{2} \alpha_{1}\right)^{2}-$ $3 \gamma_{1} \theta_{1}<0, \beta_{1}$ is the descending function of $\alpha_{2}$.

Proof of Property 2. To prove the first part, we have $\left(\mathrm{d} \beta_{1} / \mathrm{d} \beta_{2}\right)=\left(Z_{2} \alpha_{1} Z_{2} \alpha_{2}\right) /\left(2\left(Z_{2} \alpha_{1}\right)^{2}-3 \gamma_{1} \theta_{1}\right)$. For this part, $\beta_{1}$ is increasing with $\beta_{2}$ when $2\left(Z_{2} \alpha_{1}\right)^{2}-3 \gamma_{1} \theta_{1}>0$ and $\left(\mathrm{d} \beta_{1} / \mathrm{d} \beta_{2}\right)>0$. When $2\left(Z_{2} \alpha_{1}\right)^{2}-3 \gamma_{1} \theta_{1}<0$ and $\left(\mathrm{d} \beta_{1} / \mathrm{d} \beta_{2}\right)$ $<0$, on the contrary, $\beta_{1}$ is the descending function of $\beta_{2}$. For 
the second part, we have $\left(\mathrm{d} \beta_{1} / \mathrm{d} \beta_{2}\right)=\left(\left(Z_{2} \alpha_{1} Z_{2} \beta_{2}\right) /\right.$ $\left.\left(2\left(Z_{2} \alpha_{1}\right)^{2}-3 \gamma_{1} \theta_{1}\right)\right)$; when $2\left(Z_{2} \alpha_{1}\right)^{2}-3 \gamma_{1} \theta_{1}>0$ and $\left(\mathrm{d} \beta_{1} /\right.$ $\left.\mathrm{d} \alpha_{2}\right)>0$, then $\beta_{1}$ is the increasing function of $\alpha_{2}$. Thus, the property is proved.

As we see from above, the relationship between $\beta_{1}$ and $\beta_{2}$ indicates the firm's counter strategy against its competitor. For instance, the first part of the property shows that firm 1's strategy is consistent with firm 2's emissions reduction through the two periods. But, in the second part, both firms hold the opposite strategy from their competitor. On the contrary, $\alpha_{2}$ denotes the energy efficiency that also reflects an emissions reduction efficiency. Firm 1's emission abatement strategy in the second stage is affected by firm 2's abatement strategy in the first stage. A smaller $\alpha_{2}$ means that firm 1 will face a larger pressure for emissions abatement, due to the smaller unit emissions from firm 2 in the first stage. Accordingly, firm 1 should increase its abatement efforts in the second stage. In contrast, when $\alpha_{2}$ is large, firm 1 will choose a smaller abatement effort.

Taken together, firm 1's emission reduction strategies with respect to different conditions are shown in Table 2, where the resolution process can be easily extended to firm 2 .

From the above properties, we have the following inferences.

Inference 1. When both firms' marginal emissions are high in the first period, they will chose an abatement strategy in the second period. Specially, they will choose a contradictory strategy as their marginal emissions if the first stage of emissions is low.

Proof of inference 1. According to the above properties, $\beta_{1}$ is the increasing function of $\beta_{2}$ when $\alpha_{1}$ and $\alpha_{2}$ were bigger than the critical value $\left(1 / Z_{2}\right) \sqrt{\left(3 \gamma_{1} \theta_{1}\right) / 2}$, namely, both of the firms choose the follow-strategies with their competitors. On the contrary, if $\alpha_{1}$ and $\alpha_{2}$ are smaller than the critical value $\left(1 / Z_{2}\right) \sqrt{\left(3 \gamma_{1} \theta_{1}\right) / 2}, \beta_{1}$ is a decreasing function of $\beta_{2}$. It means that the firms choose the opposite strategy from their competitors.

Inference 1 also implies a feasible way for the government to decrease the system-wide emissions is to first encourage one of them to reduce their emissions. Potential policies include a carbon tax, environmental subsidy, or a carbon-trade mechanism, and so on. In a high energy-efficient industry, both of the oligarchies are willing to voluntarily cut their emissions without any external forces. In the following, we analyze the impact of each parameter on this optimal result. The relevant notations are simplified and reported in Table 3 .

Property 3. When $1-K \neq 0$ and $\alpha_{1}<F H /(F(1-K)), q_{12}^{*}$ is an increasing function of $\alpha_{1}$. When $1-K>0$ and $\alpha_{1}>(F H /(F(1-K))), q_{12}^{*}$ is a decreasing function of $\alpha_{1}$.

Proof of Property 3. $q_{12}^{*}=\left(E+F \alpha_{1}\right) /\left(H+K \alpha_{1}^{2}\right)$. We take the derivative and get Property 4 .

Property 4. When $(2 O P-2 Q M)^{2}+4 Q N^{2} P \geq 0$ and $\mathrm{Q} N<0, q_{12}^{*}$ is an increasing function of $\alpha_{2}$ while $\alpha_{1}<\alpha_{1}^{4}$ and $\alpha_{1}>\alpha_{1}{ }^{5}$. However, $q_{12}^{*}$ is a decreasing function of $\alpha_{2}$ when $\alpha_{1}^{4}<\alpha_{1}<\alpha_{1}^{5}$. When $(2 O P-2 Q M)^{2}+4 Q N^{2} P \geq 0$ and $Q N>$ 0 , then $q_{12}^{*}$ is a decreasing function of $\alpha_{2}$ while $\alpha_{1}^{4}<\alpha_{1}<\alpha_{1}^{5}$. $q_{12}^{*}$ is an increasing function of $\alpha_{2}$ while $\alpha_{1}^{4}<\alpha_{1}<\alpha_{1}^{5}$.

Proof of Property 4. Let $\alpha_{1}^{4}=((2 O P-2 Q M)+$ $\left.\sqrt{(2 O P-2 Q M)^{2}+4 Q N^{2} P}\right) /(2 Q N)$ and $\alpha_{1}^{5}=((2 O P-$ $\left.2 Q M)-\sqrt{(2 O P-2 Q M)^{2}+4 Q N^{2} P}\right) /(2 Q N)$; then, $q_{12}^{*}=$ $\left(M+N \alpha_{2}+O \alpha_{2}^{2}\right) /\left(P+Q \alpha_{2}^{2}\right)$. Thus, Property 5 is proved.

Property 5. When $(U / 2)<S<(3 U / 4), q_{12}^{*}$ is an increasing function of $\beta_{1}$. When $S<(U / 2)$ and $S>(3 U / 4), q_{12}^{*}$ is a decreasing function of $\beta_{1}$.

Proof of Property 5. If we simplify $q_{12}^{*}$ and take its derivative, then the property can be obtained.

Property 6. $q_{12}^{*}$ is a decreasing function of $\beta_{2}$.

Proof of Property 6. Given $\left(\mathrm{d} q_{12}^{*} / \mathrm{d} \beta_{1}\right)=\left(Z_{2} \alpha_{2} / 3 \gamma_{1}\right)$ $\left[1-\left(\left(z_{2} \alpha_{1}\right)^{2} /\left(2\left(z_{2} \alpha_{1}\right)^{2}-3 \gamma_{1} \theta_{1}\right)\right)\right]$, the formula $\left(\mathrm{d} q_{12}^{*} /\right.$ $\left.\mathrm{d} \beta_{1}\right)<0$ holds in all conditions. Thus, Property 6 is proved.

Inference 2. According to Property 5, firm 1 in the second period will increase its output due to the large abatement of firm 2 in the second stage. Intuitively, it offers a good opportunity for the firm to seize market share, while its competitor spends more effort in an emissions reduction.

\section{Numerical Analysis}

In this section, we numerically test the theoretical insights derived from our model. Two giant Chinese airlines $S$ and $E$ are chosen as a case study due to their large market shares (the real names of these two firms are omitted due to their requests for confidentiality). The real names are omitted due to the commercial confidentialities. Accordingly, the output $q$ can be used to denote their transportation seating capacity, e.g., the total seat numbers of the company; $\alpha$ denotes the carbon emissions per passenger kilometer traveled. This notation in practice can be used to measure the carbon footprint of an airline's network ( $\mathrm{Ma}$ et al.). The division of its value in the two stages of our gaming model can be used to represent $\beta$. For every percentage point dropped in $\beta$, an airline has to pay a technical improvement $\operatorname{cost} \theta$. The dataset is of a six-year length, including the information about profit margins, transportation costs, and emissions efficiency. Based on this, we set $\gamma_{1}=1.13, \gamma_{2}=0.35, Z_{1}=5$, and $Z_{2}=15$. With a linear regression, we get $a=5642$. We also set $\delta_{1}=3.5244$ and $\delta_{2}=19$ based on China's carbon emission reduction policy. Other related specific values of the notations will be, if there is no special requirement, simulated to facilitate the experiment. 


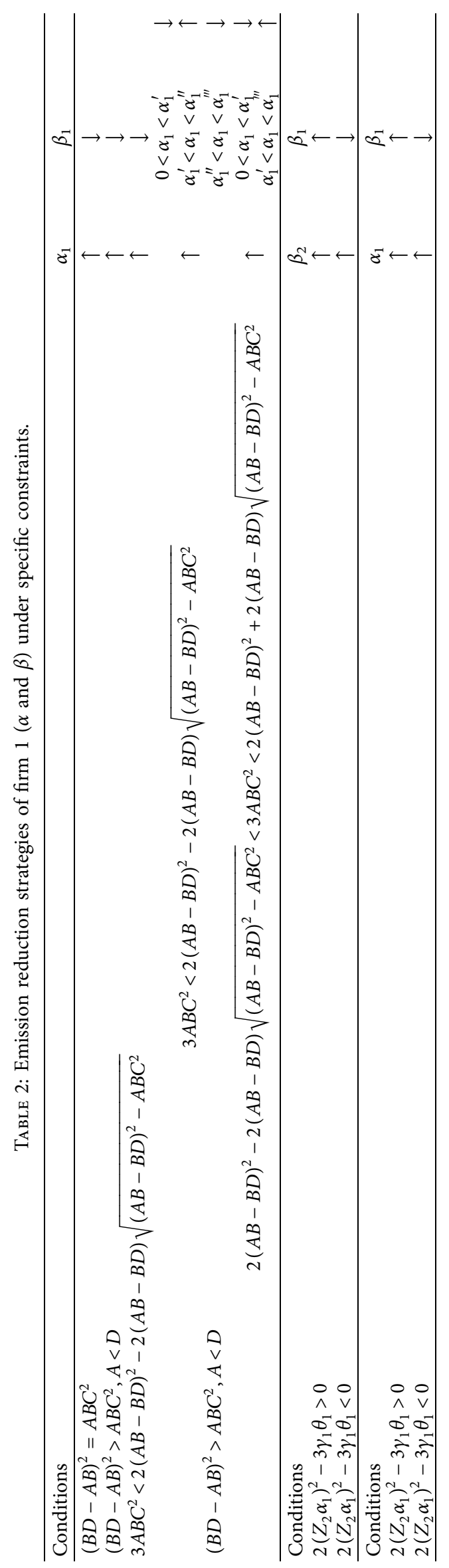


TABLE 3: Impact of the parameters to the result along with corresponding abbreviated notations.

\begin{tabular}{lc}
\hline$E$ & {$\left[a \theta_{1} \theta_{2}+Z_{2} \alpha_{2} \theta_{1} \theta_{2}+Z_{2} \delta_{2} \theta_{1} \theta_{2}\left(q_{21} /\left(q_{11}+q_{21}\right)\right) \alpha_{2}\right]\left[3 \gamma_{2} \theta_{1} \theta_{2}-2\left(Z_{2} \alpha_{2}\right)^{2} \theta_{1}\right]$} \\
& $-\left[a \theta_{1} \theta_{2}-2 Z_{2} \alpha_{2} \theta_{1} \theta_{2}+Z_{2} \delta_{2} \theta_{1} \theta_{2}\left(q_{21} /\left(q_{11}+q_{21}\right) \alpha_{2}\right)\right]\left(Z_{2} \alpha_{2}\right)^{2} \theta_{1}$ \\
$F$ & {$\left[-2 Z_{2} \theta_{1} \theta_{2}+Z_{2} \delta_{2} \theta_{1} \theta_{2}\left(q_{11} /\left(q_{11}+q_{21}\right)\right) \alpha_{2}\right]\left[3 \gamma_{2} \theta_{1} \theta_{2}-2\left(Z_{2} \alpha_{2}\right)^{2} \theta_{1}\right]$} \\
& $-\left[Z \theta_{1} \theta_{2}+2 Z_{2} \alpha_{2} \theta_{1} \theta_{2}+Z_{2} \delta_{2} \theta_{1} \theta_{2}\left(q_{21} /\left(q_{11}+q_{21}\right) \alpha_{2}\right)\right]\left(Z_{2} \alpha_{2}\right)^{2} \theta_{1}$ \\
$H$ & $3 \gamma_{2} \theta_{1} \theta_{2}-\left[3 \gamma_{2} \theta_{1} \theta_{2}-2\left(Z_{2} \alpha_{2}\right)^{2} \theta_{1}\right]$ \\
$K$ & $-2 Z_{2}^{2} \theta_{2}-\left[3 \gamma_{2} \theta_{1} \theta_{2}-2\left(Z_{2} \alpha_{2}\right)^{2} \theta_{1}\right]-Z_{2}^{2}\left(Z_{2} \alpha_{2}\right)^{2} \theta_{1} \theta_{2}$ \\
$M$ & $3 \gamma_{2} \theta_{1} \theta_{2}\left[a \theta_{1} \theta_{2}-2 Z_{2} \alpha_{1} \theta_{1} \theta_{2}+Z_{2} \delta_{2} \theta_{1} \theta_{2}\left(q_{11} /\left(q_{11}+q_{21}\right) \alpha_{1}\right)\right]$ \\
$N$ & $3 \gamma_{2} \theta_{1} \theta_{2}\left[Z_{2} \theta_{1} \theta_{2}+Z_{2} \delta_{2} \theta_{1} \theta_{2}\left(q_{21} /\left(q_{11}+q_{21}\right)\right)\right]$ \\
$O$ & $-2 Z_{2}^{2} \theta_{1}\left[a \theta_{1} \theta_{2}-2 Z_{2} \alpha_{1} \theta_{1} \theta_{2}+Z_{2} \delta_{2} \theta_{1} \theta_{2}\left(q_{11} /\left(q_{11}+q_{21}\right)\right) \alpha_{1}\right]-3 \gamma_{2} \theta_{1} \theta_{2}\left[a \theta_{1} \theta_{2}+Z_{2} \alpha_{1} \theta_{1} \theta_{2}+Z_{2} \delta_{2} \theta_{1} \theta_{2}\left(q_{11} /\left(q_{11}+q_{21}\right) \alpha_{1}\right)\right]$ \\
$P$ & $3 \gamma_{2} \theta_{1} \theta_{2}\left(3 \gamma_{1} \theta_{1} \theta_{2}-2 Z_{2}^{2} \theta_{2} \alpha_{1}^{2}\right)$ \\
$Q$ & $-2 Z_{2}^{2} \theta_{2}\left(3 \gamma_{1} \theta_{1} \theta_{2}-2 Z_{2}^{2} \theta_{2} \alpha_{1}^{2}\right)-Z_{2}^{2}\left(Z_{2} \alpha_{1}\right)^{2} \theta_{1} \theta_{2}$ \\
$S$ & $\left(z_{2} a_{2}\right)^{2}$ \\
$U$ & $\left(3 \gamma_{2} \theta_{2}\right)$ \\
\hline
\end{tabular}

5.1. The Optimal Strategy of the First Period. Figure 4(a) shows that $q_{11}^{*}\left(q_{12}^{*}\right)$ is decreasing (increasing) with each increment of $\alpha_{1}$, leaving $\alpha_{2}$ fixed; with $\alpha_{1}$ fixed, $q_{11}^{*}\left(q_{12}^{*}\right)$ is increasing (decreasing) with $\alpha_{2}$ (Figure 4(b)).

From the above graphical illustration, we find that if unit emissions increase, that decreases a firm's service capacity in the first stage due to the large marginal emissions for each output unit. In this case, a competitor will accordingly increase its output, consistent with our findings in the previous theoretical analysis.
5.2. Profit Maximization. We next analyze the influence of the marginal emissions $\alpha$, emissions abatement intensity $\beta$, and unit technology improvement $\operatorname{cost} \theta$ on profit and carry out an equilibrium analysis. The total profit function, $L$, listed as follows, is the sum of the profits from two periods for each firm:

$$
\begin{aligned}
& L_{1}=\left(a-\gamma_{1} q_{11}-\gamma_{2} q_{21}\right) q_{11}-Z_{1}\left(\alpha_{1} q_{11}-\delta_{1} r_{1} A\right)+\left(a-\gamma_{1} q_{12}-\gamma_{2} q_{22}\right) q_{12}-Z_{2}\left(\beta_{1} \alpha_{1} q_{12}-\delta_{2} \bar{\alpha} q_{12}\right)-\frac{1}{2} \theta_{1}\left(1-\beta_{1}\right)^{2} \\
& L_{2}=\left(a-\gamma_{1} q_{11}-\gamma_{2} q_{21}\right) q_{21}-Z_{1}\left(\alpha_{2} q_{21}-\delta_{1} r_{2} A\right)+\left(a-\gamma_{1} q_{12}-\gamma_{2} q_{22}\right) q_{22}-Z_{2}\left(\beta_{2} \alpha_{2} q_{22}-\delta_{2} \bar{\alpha} q_{22}\right)-\frac{1}{2} \theta_{2}\left(1-\beta_{2}\right)^{2} .
\end{aligned}
$$

Remark 2. As the marginal emissions $\alpha$ decreases in the first period, the total profits of the two companies $L_{1}$ and $L_{2}$ increase. Let $\beta_{1}=\beta_{2}=0.85, \theta_{1}=200000000, \theta_{2}=$ $100000000, \alpha_{1} \in(0,15)$, and $\alpha_{2} \in(0,20)$.

The total profit functions for both firms can then be graphically depicted in Figures 5(a) and 5(b), respectively. The black slant lines in the figure denote the profit isoline. It means that the points in the same profit isoline have the same total profit values. The points along an isoline represent different combination patterns of $\alpha_{1}$ and $\alpha_{2}$ subject to a single profit value. The different black slant lines from the bottom left (dark area) to the top right (light color area) are the tiered profit lines that reflect the total profit increases with the variation of $\alpha$. From the tiered profit lines, we can see, for airline 1 , the profit line is pushed toward the upper right corner as $\alpha_{1}$ and $\alpha_{2}$ increase, namely, the total profit of firm 1 increases as its unit emissions decline in the first period. The analysis of airline 2 is similar; from Figure 5(b), the profit line is pushed to the upper right corner as $\alpha_{1}$ and $\alpha_{2}$ increase, meaning that its total profit increases.

Following the above result, inferences are drawn below.

Remark 3. As the emission abatement intensity increases $(\beta$ decreases), the total profits of the two airlines increase at first and then decrease, going through a maximum point for a particular value of $\beta$.

Let $\alpha_{1}=15, \quad \alpha_{2}=20, \quad \beta_{1} \in(0,1), \quad \beta_{2} \in(0,1), \quad \theta_{1}=$ 200000000, and $\theta_{2}=100000000$. With these choices, we draw the total profit as shown in Figures 6(a) and 6(b) of airline 1 and airline 2, respectively. Similar to Figures 5(a) and 5(b), the black slant lines in the figure denote the profit isoline. It means that the points in the same profit isoline have the same total profit values. The points along an isoline represent different combination patterns of $\beta_{1}$ and $\beta_{2}$ are 


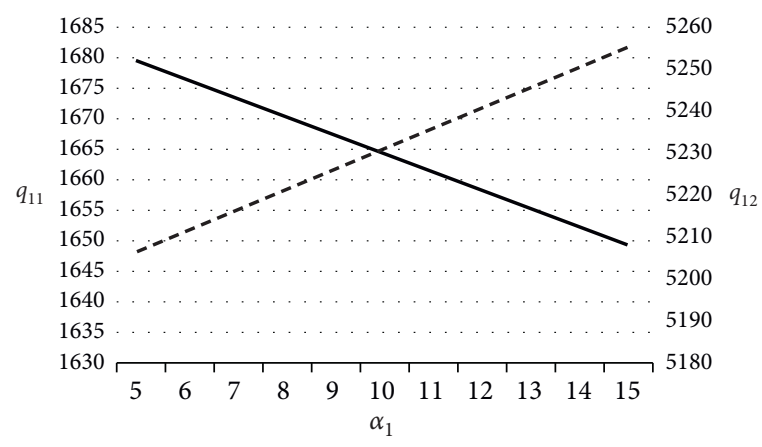

$-\begin{array}{ll}- & q_{11} * \\ -- & q_{12} *\end{array}$

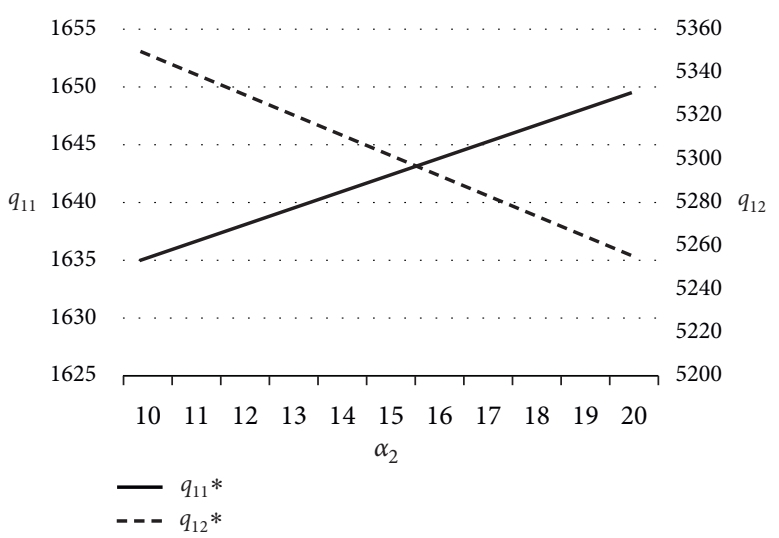

(b)

FIgURE 4: (a) Keeping $\alpha_{2}$ constant, with $\alpha_{1}$ increasing, $q_{11}^{*}$ is decreasing (solid line) and $q_{12}^{*}$ is increasing (dotted line). (b) Keeping $\alpha_{1}$ constant, with $\alpha_{2}$ increasing, $q_{11}^{*}$ is increasing (solid line) and $q_{12}^{*}$ is decreasing (dotted line).

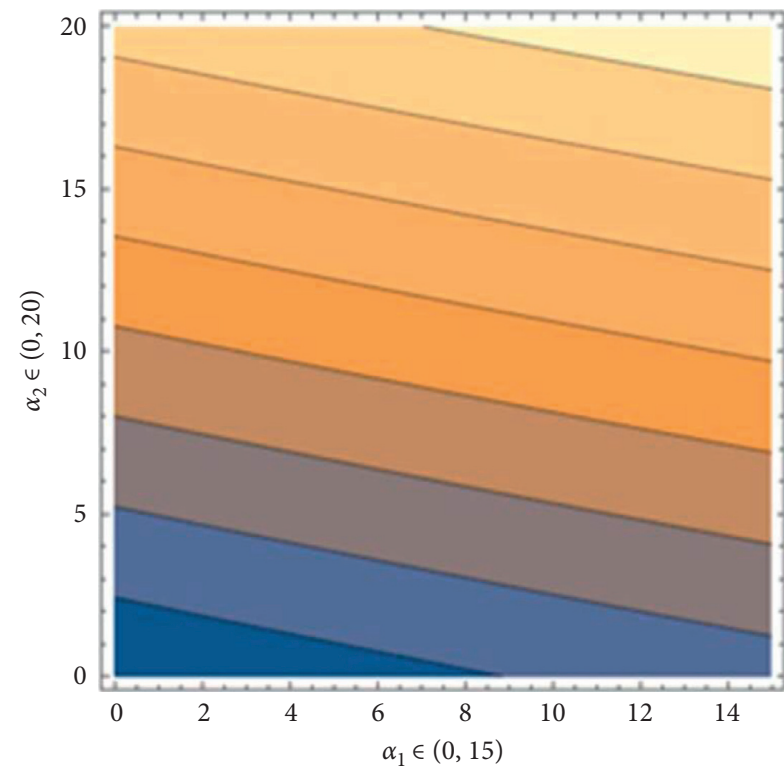

(a)

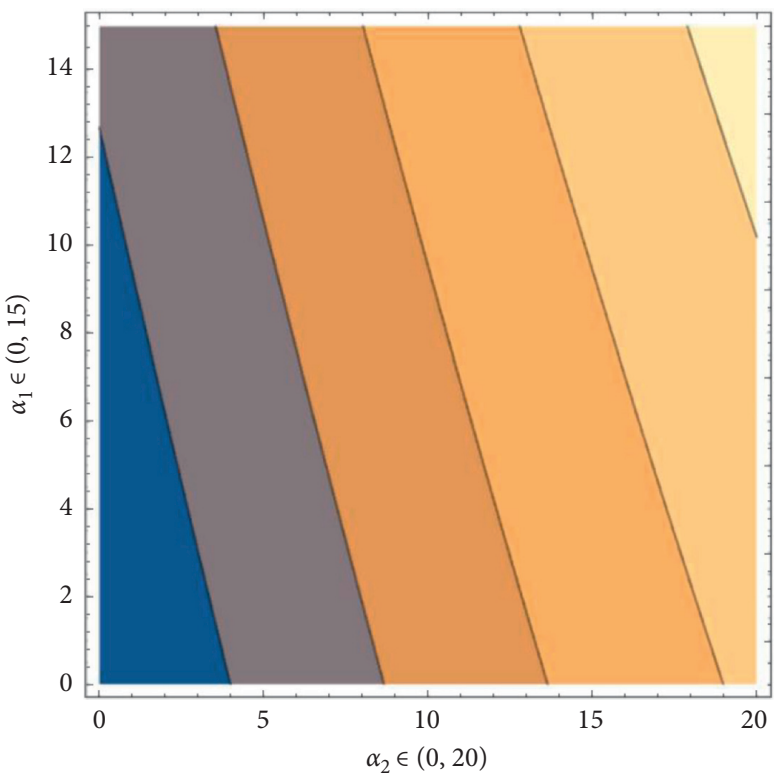

(b)

Figure 5: (a) The profit line of airline 1 is pushed toward the upper right corner as $\alpha_{1}$ and $\alpha_{2}$ increase. (b) The profit line of airline 2 is pushed toward the upper right corner as $\alpha_{1}$ and $\alpha_{2}$ increase.

subject to a single profit value. The different black slant lines from the dark area (left for Figures 6(a) and bottom for 6(b)) to the light color area (right for Figures 6(a) and top for 6(b)) are the tiered profit lines that reflect the total profit increases with the variation of $\beta$.

For airline 1, the tiered profit lines move to the lighter colored area at the beginning and reach the maximum when $\beta_{1}=\beta_{1}^{*}$; then, they move to the lower left corner with each increment of $\beta_{1}$ and $\beta_{2}$ together. In other words, as $\beta$ increases, the total profit increases at first and then decreases following its maximum value obtained at $\beta_{1}=\beta_{1}^{*}$. Intuitively, if airline 1 chooses to lower its emission abatement intensity in the second period (the greater value of $\beta_{1}$ means low emission reduction), in order to minimize its losses from carbon emissions cost, airline 1 can reduce output, raising market prices to balance the spending. Consequently, the carbon emission cost decreases and the profit increases. When the intensity of emission reduction reduces to a certain value (the turning point in the figure), the increased technology cost of emission reduction cannot be offset by the benefit from emission abatement, and the profit begins to decrease as the intensity of emission reduction continues to decrease. The analysis of airline 2 is similar; the total profit increases and reaches a maximum when $\beta_{2}=\beta_{2}^{*}$ and then decreases as $\beta_{2}$ decreases (Figure 6(b)).

From the above result, we have the following inference.

Inference 3. The emission reduction strategies of the two airlines can achieve equilibrium in the second period.

According to Figure 6(a), when $\beta_{1}$ is less than $\beta_{1}^{*}, \beta_{1}$ is the decreasing function of $\beta_{2}$ in the profit equilibrium, $\beta_{2}$ decreases as $\beta_{1}$ increases, and $\beta_{2}$ increases as $\beta_{1}$ decreases, 


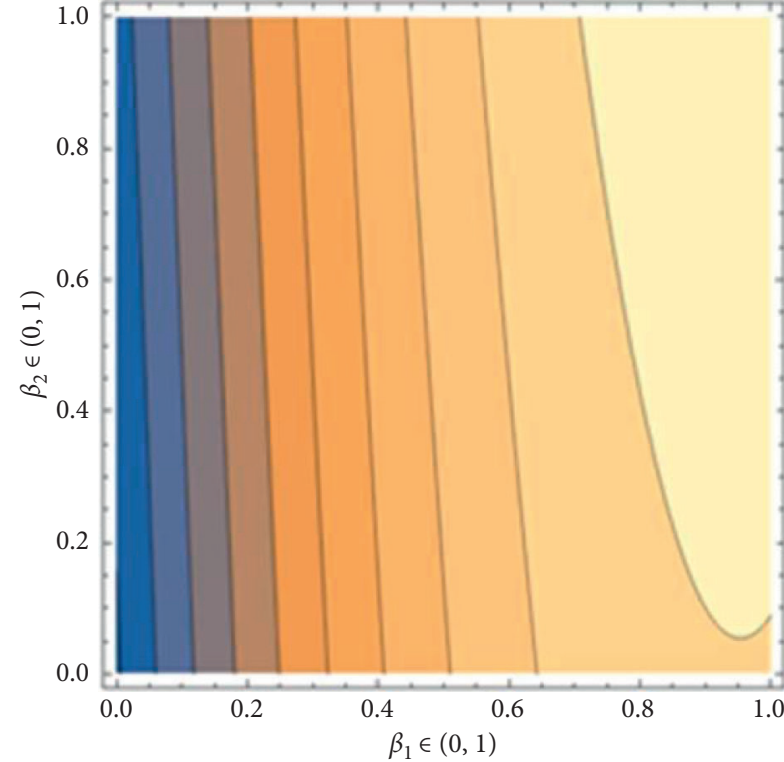

(a)

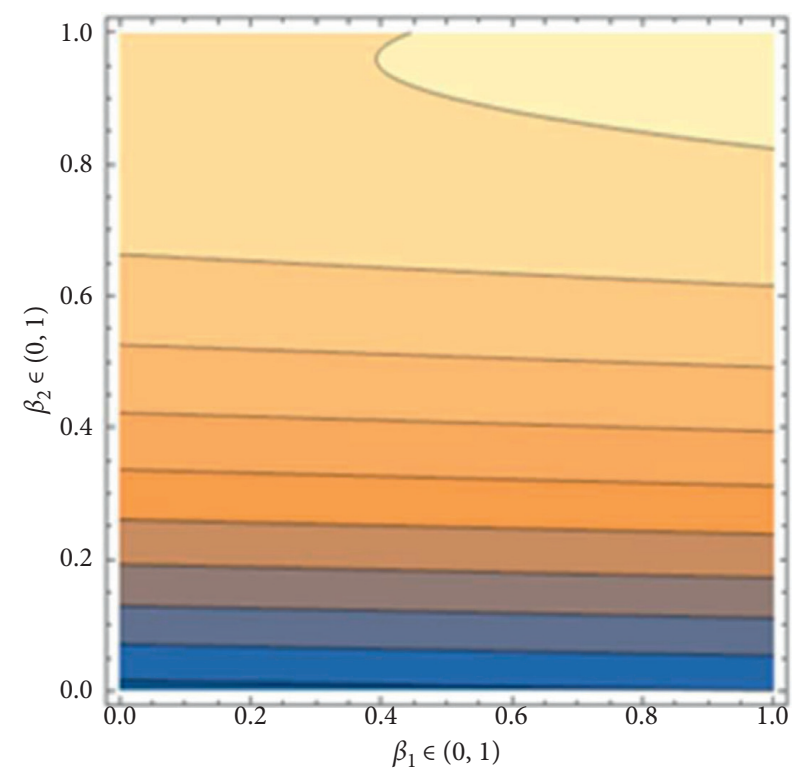

(b)

Figure 6: (a) As $\beta$ increases, the total profit of airline 1 increases at first and then decreases after it reaches the maximum at $\beta_{1}=\beta_{1}^{*}$. (b) As $\beta$ increases, the total profit of airline 2 increases at first and then decreases after it reaches the maximum at $\beta_{2}=\beta_{2}^{*}$.

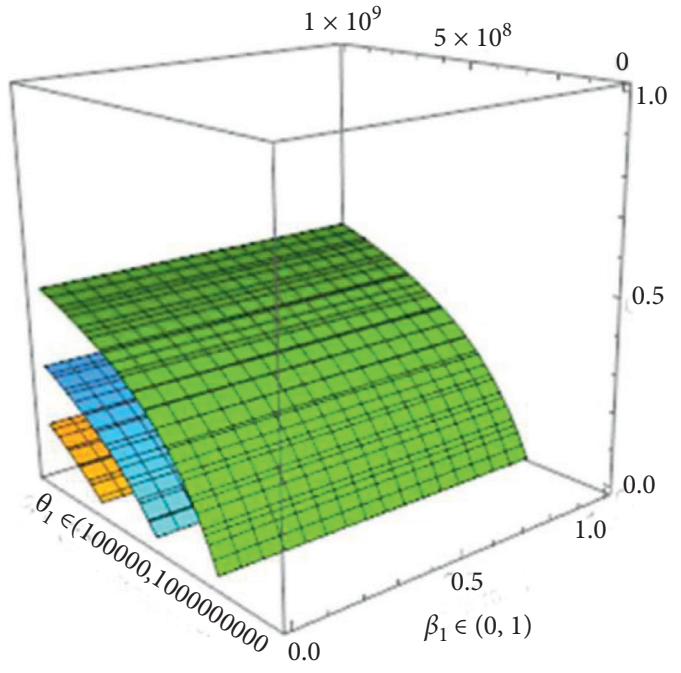

(a)

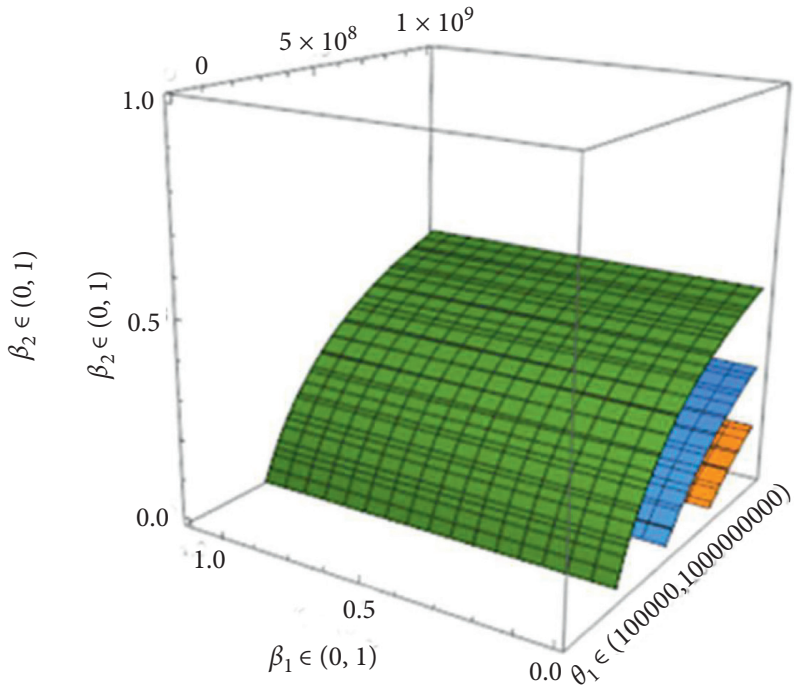

(b)

Figure 7: (a) Airline 1's total profit increases as $\theta_{1}$ decreases for a given $\beta_{1}$ and $\beta_{2}$. (b) Airline 2's total profit increases as $\theta_{2}$ decreases for a given $\beta_{1}$ and $\beta_{2}$.

which means airline 1 is employing the opposite strategy against airline 2 when airline 1 increases its energy efficiency in the second period. When $\beta_{1}$ is greater than $\beta_{1}^{*}, \beta_{1}$ is the increasing function of $\beta_{2}$ at the equilibrium of profits, $\beta_{2}$ increases as $\beta_{1}$ increases, and $\beta_{2}$ decreases as $\beta_{1}$ decreases, namely, airline 1 is employing a cooperative strategy with airline 2 when airline 1 chooses to implement a higher marginal emissions target in the second period. Identical results for airline 2 can be graphically observed in Figure 6(b): when $\beta_{2}$ is less than $\beta_{2}^{*}$, airline 2 employs the opposite strategy against airline 1 by choosing a low marginal emissions target in the second period. When $\beta_{2}$ is greater than $\beta_{2}^{*}$, airline 2 employs a cooperative strategy with airline 1 that airline 2 chooses low energy efficiency in the second period. In summary, the value of $\beta$ will be infinitely close to $\beta^{*}$ when both airlines want to maximize their own profit. This inference indicates that, in the carbon emissions trading system, the buyer and seller, under some conditions, can reach equilibrium but it is a win-loss situation. 
Remark 4. Decreasing the input of emissions reduction technology increases total profits, while increasing the emission abatement intensity.

Setting $\alpha_{1}=15, \alpha_{2}=20, \beta_{1} \in(0,1), \beta_{2} \in(0,1)$, $\theta_{1}=200000000$, and $\theta_{2}=100000000$, we draw the total profits in Figures 7(a) and 7(b). The curved surfaces in the figures are profit isosurfaces. It means that the points in the same profit isosurfaces have the same total profit values. The points on the same surface reflect different combinations of $\beta$ and $\theta$ under the same profit level. The surfaces pushing from the bottom left corner (the bottom right corner for Figures 7(b)) to the top right corner (the top left corner for Figures $7(b)$ ) are tiered profit surfaces that reflect the total profit increased with the variation of $\beta$ and $\theta$.

According to the profit isograms in Figure $7(\mathrm{a})$, airline 1 's total profit increases as $\theta_{1}$ decreases for a given $\beta_{1}$ and $\beta_{2}$. Under the same conditions, profit increases as the technological improvement cost decreases. The same logic exist in airline 2 in Figures 7 (b) since its total profit increases as $\theta_{2}$ decreases for a given certain $\beta_{1}$ and $\beta_{2}$.

Inference 4. According to the profit line in the figure above, as the unit cost of technological improvement decreases, airline 1 can increase its emission reduction efforts while maintaining its original profit. Similarly, airline 2 could increase its emissions cuts while maintaining its profits. It can be seen that reducing the cost of emission reduction technology cannot only increase the total profit of the company but also improve the intensity of emission reduction of the company. So, for the competing firm, reducing the emissions abatement technological investment is a way to incentivise the firms to carry out low-carbon campaigns.

\section{Conclusion}

From the enterprise's perspective, this study discusses how to make production and emission reduction strategies to achieve the maximum profit under the pressures of an oligopolic competition and low-carbon regulation. From the results, the equilibrium exists in profit maximization rather than emissions minimization. In the equilibrium state, both firms will implement a high-emissions strategy in the first period and continue on a low energy-efficient strategy in the second period if they lack an external driving force. On the contrary, we found the firms capable of collectively reaching the maximum profit by balancing their output and adjusting their emissions abatement intensities. We carried out a case study for a set of data from two Chinese airlines. The result illustrated possible reasons behind a passive attitude toward low-carbon regulations, e.g., inadequate carbon trading mechanism. For instance, the technology improvement will bring about a high emissions abatement cost and lead to negative responses of the firms to the regulations. Also, we found that if there is no other incentive, the firms will choose to reduce their emissions based on a regulation's requirement. For a Cournot game, equilibrium can be reached between the firms, although both of them will play the opposite strategies under some conditions.
In order to provide the government and industry with suggestions, two effective ways for emissions reduction are proposed. For the government, some policies or regulative tools are encouraged to stimulate the low energy-efficiency firms to reduce their emissions, including a carbon tax, environmental subsidies, or a carbon trade mechanism. For the firm, we suggested that it reduce its emissions-reducing technological cost for a low-carbon [14] environment.

\section{Data Availability}

The six-year length information about profit margin, transportation cost, and emission efficiency of airlines used to support the findings of this study were supplied by China Southern Airlines and Air China under license and so cannot be made freely available. Requests for access to these data should be made to Si Min Zhang (lingberyl@ 163.com\&rdquo).

\section{Disclosure}

The value of notations used to support the findings of this study are included within the article.

\section{Conflicts of Interest}

The authors declare that there are no conflicts of interest regarding the publication of this paper.

\section{Acknowledgments}

This work was supported by National Natural Science Foundation of China, Research on Supply Network Optimization in the Context of Omni-Channel Retail, 71771222. The authors also thank Guangdong Regional Financial Policy Research Center for its support.

\section{References}

[1] J. Li and S. Li, "Energy investment, economic growth and carbon emissions in China-empirical analysis based on spatial Durbin mode," Energy Policy, vol. 140, Article ID $111425,2020$.

[2] J. Ma, Y. Hou, Z. Wang, and W. Yang, "Pricing strategy and coordination of automobile manufacturers based on government intervention and carbon emission reduction," Energy Policy, vol. 148, p. 111919, 2021.

[3] S. R. Madani and M. Rasti-Barzoki, "Sustainable supply chain management with pricing, greening and governmental tariffs determining strategies: a game-theoretic approach," Computers \& Industrial Engineering, vol. 105, pp. 287-298, 2017.

[4] C. Feng, H. Zhang, and J. B. Huang, "The approach to realizing the potential of emissions reduction in China: an implication from data envelopment," Renewable and Sustainable Energy Reviews, vol. 71, pp. 859-872, 2017.

[5] M. H. Babiker, "Climate change policy, market structure, and carbon leakage," Journal of International Economics, vol. 65, no. 2, pp. 421-445, 2005.

[6] N. Sabzevar, S. T. Enns, J. Bergerson, and J. Kettunen, "Modeling competitive firms' performance under price-sensitive demand and cap-and-trade emissions constraints," 
International Journal of Production Economics, vol. 184, pp. 193-209, 2017.

[7] F. H. Wen, L. L. Zhao, S. Y. He, and G. Z. Yang, "Asymmetric relationship between carbon emission trading market and stock market: evidences from China," Energy Economics, vol. 91, p. 104850, 2020.

[8] X. Xu, W. Zhang, P. He, and X. Xu, "Production and pricing problems in make-to-order supply chain with cap-and-trade regulation," Omega, vol. 66, pp. 248-257, 2017.

[9] W. Tong, D. Mu, F. Zhao, G. P. Mendis, and J. W. Sutherland, "The impact of cap-and-trade mechanism and consumers" environmental preferences on a retailer-led supply chain," Resources, Conservation and Recycling, vol. 142, pp. 88-100, 2019.

[10] K. Cao, P. He, and Z. Liu, "Production and pricing decisions in a dual-channel supply chain under remanufacturing subsidy policy and carbon tax policy," Journal of the Operational Research Society, vol. 71, pp. 1-17, 2020.

[11] J. Y. Lee, "Investing in carbon emissions reduction in the EOQ model," Journal of the Operational Research Society, vol. 71, no. 8, pp. 1289-1300, 2020.

[12] R. Y. Sinaki, A. Sadeghi, G. Suer et al., "A weighted multiobjective mathematical model for cell scheduling and environmentally sustainable supply chain network," Procedia Manufacturing, vol. 39, pp. 1559-1566, 2019.

[13] X. Chen, X. Wang, V. Kumar, and N. Kumar, "Low carbon warehouse management under cap-and-trade policy," Journal of Cleaner Production, vol. 139, pp. 894-904, 2021.

[14] Q. Bai, Y. Gong, M. Jin, and X. Xu, "Effects of carbon emission reduction on supply chain coordination with vendor-managed deteriorating product inventory," International Journal of Production Economics, vol. 208, pp. 93-99, 2019. 